\title{
Study on the Law of Surface Cracks While Coal Mining in the Thin Bedrock and Thick Unconsolidated Layer of Yu-Shen-Fu Mining Area
}

\author{
Wu Zuoqi ${ }^{1,2}$, Wang Guoku'1,2, Zhao Liqin ${ }^{1,2}$ \\ ${ }^{1}$ Mine Safety Technology Branch of China coal research institute, Beijing 100013, China \\ ${ }^{2}$ State Key Laboratory of Coal Mining and Clean Utilization (China Coal Research Institute, Beijing 100013, China
}

\begin{abstract}
The law of surface cracks caused by coal mining in ther thin bedrock and thick unconsolidated layer was studied in Yu-Shen-Fu mining area. The crack development in the overlying strata of the coal mining face was detected by drilling survey technology, the whole process of the ground surface crack dynamic evolution was carried out by similar material simulation, and the law of surface cracks evolution was verified by on-site tracking measurement. The study reached the regulation of the overlying strata failure and dynamic evolution of surface cracks caused by coal mining under thin bedrock and thick unconsolidated layer in Yu-Shen-Fu mining area, which can provide theoretical support for the ecological restoration of western mining area.
\end{abstract}

\section{INTRODUCTION}

While large-scale coal resource exploitation supported national construction, it has also induced a series of serious mining disasters ${ }^{[1-4]}$. Especially the mining safety problems and environmental damage caused by coal mining under special geological mining conditions, are becoming more and more serious, which affect safe production of coal mining enterprises and the normal life of people in mining area. Safe production is the first priority to the development and utilization of coal resources. Equal attentions to the development and utilization of resources and the environmental protection are in line with the trend of modern coal enterprises, so as to achieve sustainable development and green mining in mining area ${ }^{[5-8]}$. Therefore, the key technological challenges, which can lead to coordinated development of coal resources safe utilization with the ecological environment protection, are urgent to be broken.

As a typical form of surface damage for the goaf, surface cracks have a serious impact on the environment and safety in mining area. The main forms of influence are divided into the following aspects: (1) Damage to ground buildings and structures. The effects of underground mining on the surface are divided into vertical and horizontal movements and deformations. Buildings and structures within the influence of the goaf are subject to the process from stationary to moving to stationary, in which process buildings and structures deformation or damage will occur after undergoing one or more kinds of forces, if the damage is serious, it will not be repaired resulting in losing its using value. (2) Damage to ground transportation facilities. The traffic facilities such as roads, railways, pipelines and transmission lines within the influence of the goaf will undergo local strains such as stretching, compression and distortion under the influence of the goaf. When the deformation reaches a certain level, the traffic facilities will be partially damaged. (3) Soil erosion. While the coal resources are mined, the caving zone and the fracture zone of the goaf will develop into a loose aquifer, and the aquifer will be drained to form a precipitation funnel, resulting in a large loss of surface water. According to statistics, coal mining has formed more than 150 regional precipitation funnels in the country, with a total funnel area of 87,000 square kilometers. Soil erosion has caused more serious damage to the otherwise fragile ecological environment in western China. (4) Water and sand inrush of working face. Under the condition that the working face tends to be fully plucked in the width direction, the caving zone formed by the overlying strata in the goaf will rapidly develop into a loose aquifer with strong water-richness, and the loose sand body will flow into the working face through the falling crack under the action of self-weight stress and hydraulic force, causing water and sand inrush accident. The surface cracks obtained by a large number of on-site investigations is shown in Figure 1.

\footnotetext{
* Corresponding author: shandongwzq87@163.com.
} 


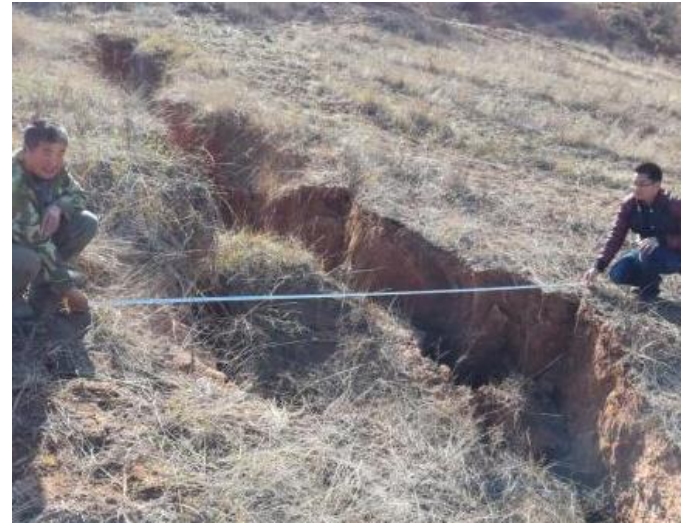

Figure 1. Disaster overview of surface cracks caused by mining

\section{DRILLING SURVEY OF TYPICAL WORKING FACE OVERLYING STRATA DAMAGE}

Typical working face was selected in Yu-Shen-Fu mining area to carry out the drilling survey research, by which we deeply studied the surface cracks development law caused by coal mining under thin bedrock and thick unconsolidated layer. The minimum thickness of bedrock in the bottom area of ancient gully ditch was $24.8 \mathrm{~m}$, the thickness of unconsolidated layer was $20 \sim 30 \mathrm{~m}$, the average thickness of the bedrock in the uphill area was $40 \mathrm{~m}$, and the average thickness of unconsolidated layer was $25 \mathrm{~m}$. The drilling survey was carried out by means of comparative analysis of the preharvest hole and the post-harvest hole, according to China's current coal industry standard MTT865-2000 "Drilling fluid leakage observation method for the height of the water-conducting crack zone", the drilling time of the post-harvest hole was 45 days after the working face was advanced. The drilling layout topography was shown in Figure 2. The drilling survey used the combination method of borehole flushing fluid leakage monitoring and colourful borehole televiewer peeping to obtain the internal fault characteristics of the overlying strata.

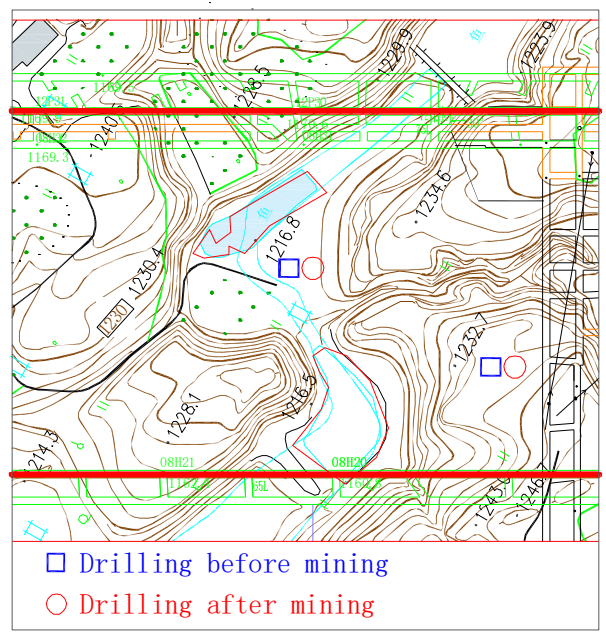

Figure 2. Location design of drilling survey
There was no obvious loss during the drilling of the pre-harvest hole, indicating that there was no primary crack development at the drilling location. The drilling rig at the bottom of the ancient gully ditch drilled to $17.9 \mathrm{~m}$, "did not return water", during the drilling of the post-harvest hole, and there was a "suction" phenomenon in the orifice. It was also clear that the inner wall of the borehole in the "suction" position had obvious cracking by borehole televiewer image, and the inner wall of the borehole in the lower section of the "suction" position had different degrees of cracking, as shown in Figure 3. Therefore, it can be concluded from the leakage of the flushing liquid and the borehole televiewer image, the water-conducting fissure zone at the bottom of the ancient gully can be developed to at least the "suction" position, in another word, the development height of the water-conducting fracture zone is at least $25.8 \mathrm{~m}$.

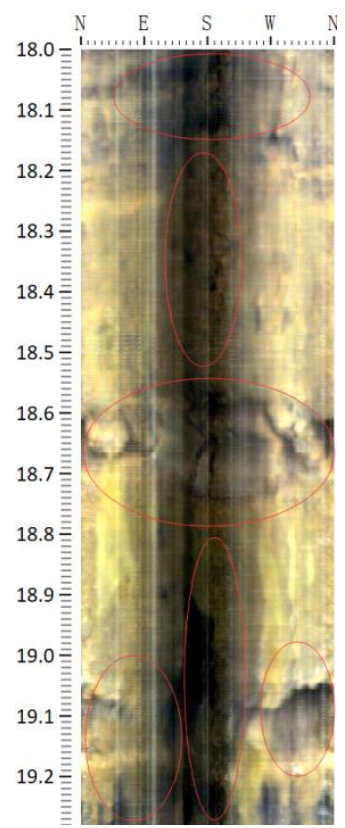

Figure 3. Image of the hole in the bottom of the bottom of the $\mathrm{Gu}$ Chonggou trench

When the rear hole is drilled up to $20.7 \mathrm{~m}$, the rig "did not return water" and there was a "suction" phenomenon in the orifice. Through the borehole televiewer image, it was also clear that there was obvious cracking on the inner wall of the borehole in the "suction" position, and the inner wall of the borehole in the lower section of the "suction" position has different degrees of cracking which is shown in Figure 4. 


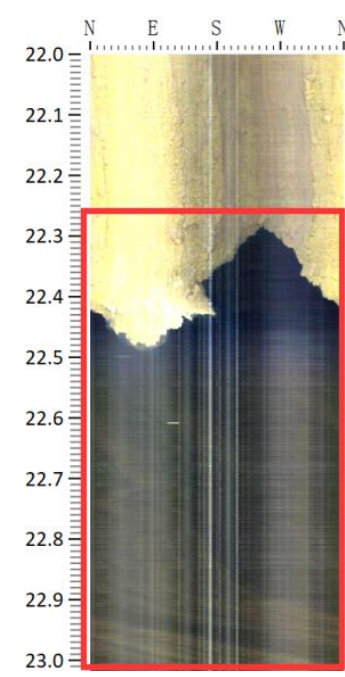

Figure 4. Inside the hole in the uphill area

The surface of the bottom of the ancient gully ditch was the Quaternary unconsolidated layer, and the base rock part began at 22.08 meters below the surface. The surface of the ditch uphill area was the Quaternary unconsolidated layer, and the base rock part began at 22.40 meters below the surface. The presence of the unconsolidated layer on the surface of the ditch and the uphill slope prevents the smoothness of water conduction between the surface and the goaf. Therefore, the water-conducting fissure zone at the bottom of the trench and the uphill slope of the trench can be identified as the location of "water leakage and suction". The specific drilling analysis results were shown in Table 1.

Table 1 .Statistical Table of Development Survey Results of Falling and Fracture Height

\begin{tabular}{ccc}
\hline $\begin{array}{c}\text { Drilling } \\
\text { position }\end{array}$ & $\begin{array}{c}\text { Falling } \\
\text { height }(\mathbf{m})\end{array}$ & $\begin{array}{c}\text { fracture height } \\
(\mathbf{m})\end{array}$ \\
\hline Ancient gully & 10.1 & 25.8 \\
Ditch uphill & 21.18 & 51.56 \\
\hline
\end{tabular}

\section{EXPERIMENTAL STUDY ON OVERLYING STRATA FAILURE OF COAL MINING UNDER THIN BEDROCK AND THICK UNCONSOLIDATED LAYER}

\subsection{Overview of similar material simulation experimental models}

Materials were as follows:

The similar material simulation bench used in the similar material simulation test was: length $\times$ width $\times$ height $=2.2 \mathrm{~m} \times 0.30 \mathrm{~m} \times 2.0 \mathrm{~m}$. The similar conditions for the simulation test of similar were set according to the mining area geological and mining conditions of the research object:

(1) Geometric similarity ratio:

$$
\alpha_{L}=L_{M} / L_{P}=1: 100 \text {; }
$$

(2) Time similarity ratio:

$$
\alpha_{t}=t_{M} / t_{P}=\sqrt{\alpha_{L}}=\sqrt{1: 100}=1: 10 \text {; }
$$

(3) Density similarity ratio:

$$
\alpha_{\gamma}=\gamma_{M} / \gamma_{P}=1.9 \mathrm{~g} / \mathrm{cm}^{3} / 2.7 \mathrm{~g} / \mathrm{cm}^{3}=1: 1.42 \text {; }
$$

(4) Strength similarity ratio:

$$
\alpha_{\sigma}=\sigma_{M} / \sigma_{P}=\left(\gamma_{M} * L_{M}\right) /\left(\gamma_{P} * L_{P}\right)=1: 142 \text {; }
$$

(5) External force similarity ratio:

$$
\alpha_{F}=\alpha_{\gamma} * \alpha_{L}^{3}=1: 1420000 \text {; }
$$

(6) Elastic modulus similarity ratio:

$\alpha_{E}=\sigma_{\rho} * \sigma_{L}=1: 142$

The dimensions of the similar material model were designed as follows according to the test results of the stratum intensity to be simulated and the mechanical properties of similar materials above: length $\times$ width $\times$ height $=2.2 \mathrm{~m} \times 0.30 \mathrm{~m} \times 1.2 \mathrm{~m}$. The model is a fullsurface simulation with no external force loading on the top.

\subsection{Model mining design}

The similar material simulation model design had a bedrock thickness of $35 \mathrm{~m}$, a coal seam thickness of $5 \mathrm{~m}$, a unconsolidated layer thickness of $40 \mathrm{~m}$, a simulated mining coal seam length of $120 \mathrm{~cm}$, an open-off cut $50 \mathrm{~cm}$ from the right side of the model, and a stopping line $50 \mathrm{~cm}$ from the left side of the model. The mining depth is determined according to the thickness of the overlying strata and the thickness of the unconsolidated layer. The simulation of the unconsolidated layer used the acrylic transparent plate as the front limit of the section, and the quartz sand was used as the simulated material, which did not contain the cemented component. The simulated working face mining speed was $15 \mathrm{~m} /$ day, referred to the time similarity coefficient, the model excavation speed was calculated as $10 \mathrm{~cm} / \mathrm{h}$ and the whole continuous excavation time of the designed coal seam in the model was $12 \mathrm{~h}$. The state of the experimental model before the excavation was first observed, and data was collected for each collapse occurred in the mining process. The state of the experimental model before the excavation was shown in Figure 5.

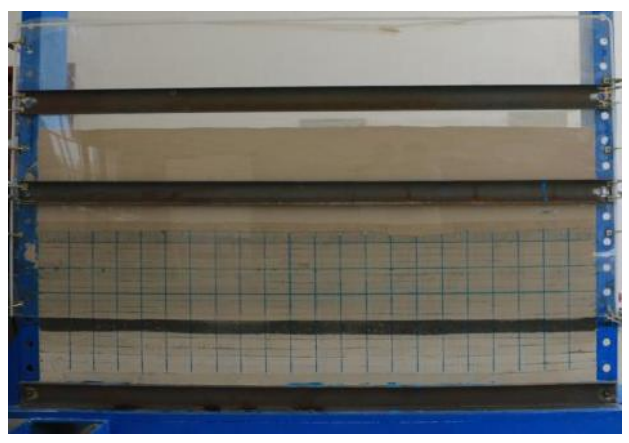

Figure 5. Initial state diagram of the model before coal mining

3.3 Monitoring of simulated coal seam mining and overlying strata damage 
The similar material simulation experiment mainly monitored the characteristics of overlying strata failure and the characteristics of unconsolidated layer movement after coal seam mining. The key research area of the similar material simulation experiment is the upper part of bedrock and the lower part of unconsolidated layer. The installation test pressure box (model XHZ-4XX) was designed $5 \mathrm{~cm}$ on the top of the overlying strata as the needs of internal stress monitoring for the similar material simulation experiment model. 10 soil test pressure box was designed, equidistant layout for every $20 \mathrm{~cm}$, sampling interval $30 \mathrm{~s}$, to monitor the impact of different levels of overlying strata internal stress changes under the influence of mining at real-time. The designed position of the soil test pressure box was shown in Figure 6.

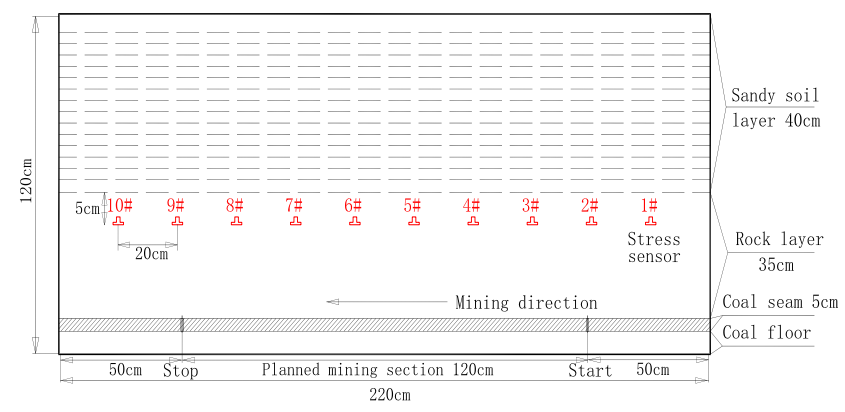

Figure 6. Similar material model stress monitoring point layout

The whole simulated coal seam was carried out at a constant speed, and the overlying strata collapse was staged collapse with the advancement of the working face. The specific phenomenon was described as follows: when the simulated coal seam was mined to $28 \mathrm{~m}$, the immediate roof of the goaf was initially collapsed; when the working face continued to advance to $39.8 \mathrm{~m}$, the immediate roof collapsed further along the direction of the working face, the fallen length increased to $36 \mathrm{~m}$, and the fallen rock layer developed upward to $9.8 \mathrm{~cm}$; when the working surface continued to advance to $46.2 \mathrm{~m}$, the fallen length of rock layer along the working surface increased to $46 \mathrm{~m}$, the vertical development increased to $15.5 \mathrm{~m}$; when the working surface continued to advance to $52 \mathrm{~m}$, two deformation processes appeared at the overlying strata in a short time. First, the fallen length of rock layer along the working surface increased to $52 \mathrm{~m}$, and the vertical development increased to $30 \mathrm{~m}$; then, the fallen rock layer directly developed to the top of the bedrock, a "sinking basin" appeared at the surface of the unconsolidated layer immediately, and cracks appeared at the edge area of the "sinking basin". The deformation state of the overlying strata at this time was shown in Figure 7; as the working face continued to advance, the overlying strata was degraded periodically, the average stepping distance was $19 \mathrm{~m}$. The surface cracks also showed periodic development.

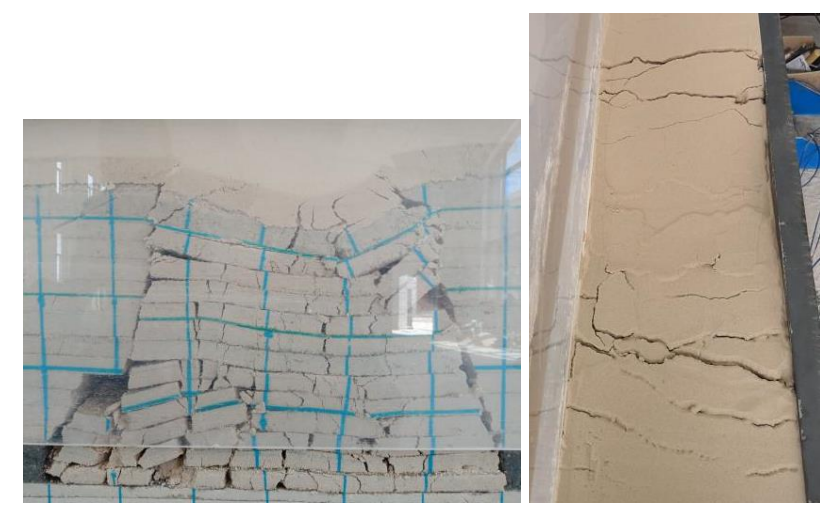

Figure 7. Deformation state and surface crack effect diagram when the overlying strata fell to the top of the bedrock

The stress curve of the pressure box with different mining progress was drawn according to the data information collected by the soil experimental pressure box , as shown in Figure 8. The internal stress change in the rock formation in the fallen area had a changing process of "supercharging-stretching-boosting", and the mining effect caused the overlying strata to fall partly. The fallen rock mass blocked the support of the lower bedrock to the upper rock mass. The load of rock mass that lost direct support was distributed to the rock mass on both sides to form "supercharging", and the mining influence developed upward to the stress monitoring area, and a "separation layer" was formed between the rock layers. The tensile stress was formed inside the rock mass. "stretching area" continued to move forward as the goaf moved, the overlying strata of the old goaf roof was gradually compacted, resulting in the formation of "pressurization" again.

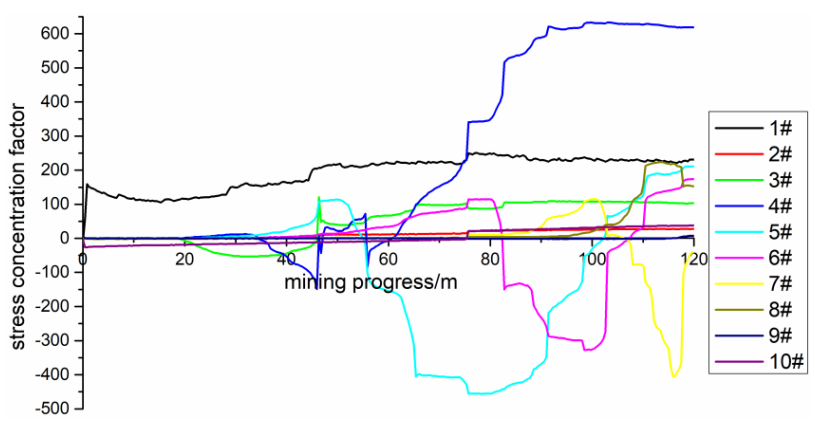

Figure 8. Deformation state and surface crack effect diagram when the overlying strata falls to the top of the bedrock

Through the actual observation of surface cracks in coal mining face and the comparison of similar material simulation experiments, it can be concluded that the surface cracks showed a dynamic process of "crackingclosing", the surface cracks, overlying strata slump and internal stress changes of rock mass showed the same spatial and time periodicity. The scene of the ground crack was shown in Figure 9. 


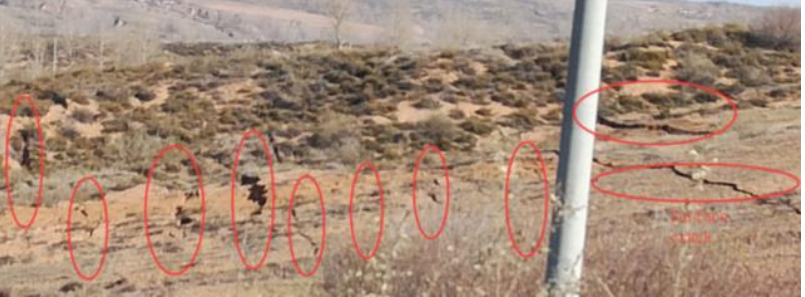

Figure 9. Field measurement overview of surface cracks

\section{CONCLUSIONS}

(1) The height of the rock stratum and the fractured zone of the goaf under thin bedrock and thick unconsolidated layer were obtained through the drilling surwey. (2) The dynamic failure law and internal stress variation of overlying rock mass in goaf were obtained through the similar materials simulation experiment. (3) Time-space synchronization of the "superchargestretch-boost" inside the rock mass and the "crack-close" of the ground crack was found through the field measurement of surface cracks.

\section{Acknowledgment}

Funding support:The innovation fund of China coal technology \& engineering group (2018QN001)

\section{Author's introduction:}

Wu Zuoqi (1987-), Men, Doctor, Graduated from Liaoning technical university in 2016, Working in Mine Safety Technology branch of China coal research institute, Research directions is mining subsidence and mining subsidence area management.

\section{REFERENCES}

1. HE Guo-qing, YANG Lun, LING Geng-di. Mining Subsidence, M. Xuzhou: China university of mining and technology press, 1994.

2. LIU Wen-sheng, WU Zuo-qi, LI Fan-yue, CUI Tiejun. On the fracturing mechanism of the igneous rock overlying the goaf. J. Journal of Safety and Environment, 2017, 17(1), 54-58.

3. HE Rong, YANG Wen-li. Analysis on surface cracking causes by high cutting and shallow depth coal mining. J. Coal Science and Technology, 2016, 44(8), 156-160, +175.

4. HU Qing-feng, CUI Xi-ming, YUAN De-bao, DENG Xu-biao. Formation Mechanism of Surface Cracks Caused by Thick Seam Mining and Hazard Analysis. J. Journal of Mining \& Safety Engineering, 2012, 29(6), 864-869.

5. GUO Jun-ting, ZOU Ding-hui, YANG Guo-zhu, CHENG Hai-tao, LI Lei-bo. Calculation Method of the Surface Cracks Width Induced by Mining Under Thick Alluvium. J. Safety in Coal Mines, 2014, 5, 170-176.
6. WU Kan, LI Liang, AO Jian-feng, HAO Gang. Discussion on Limit Development Depth of Cracks in Surface Soil Mass Caused by Mining Subsidence. J. Coal Science and Technology, 2010, 38(6), 108112.

7. LIU Wen-sheng, WU Zuo-qi, KONG Jing, CUI Tiejun. Numerical simulation for the mechanism and causes of the surface cracks due to the seam mining. J. Journal of Safety and Environment, 2016, 16(5), 135-139.

8. LIU Hui, HE Chun-gui, DENG Ka-zhong, BIAN Zheng-fu, FAN Hong-dong, LEI Shao-gang, ZHANG An-bing. Analysis of forming mechanism of collapsing ground fissure caused by mining. J. Journal of Mining \& Safety Engineering, 2013, 30(3), 380-384. 